\title{
Research and Application of Classroom Assistant Software Based on Android
}

\author{
Jianna Zhao \\ Department of Economics and Management \\ North China Electric Power University, China \\ No.689 Huadian Road, Beishi district, Baoding, 071003, \\ China \\ zhjnzhf@163.com
}

\author{
Fengyi Zhao \\ Department of Economics and Management \\ North China Electric Power University, China \\ No.689 Huadian Road, Beishi district, Baoding, 071003, \\ China \\ 409764198@qq.com
}

\begin{abstract}
In society, the use of mobile technology as a link for efficient transmission of knowledge to achieve the time and geographical restrictions on the education model has become important and urgent task combined with the development needs of China's contemporary education with the popular application of mobile information technology and rapid development of mobile phone software. Development and application of class assistant software based on Android technology connects the application design techniques of the mobile phone with the current classroom management to provide a real-time communication platform between teachers and students. Our results show that the program exerts a significant effect in the online study. The platform is convenient for teachers and students to effectively teach and study to cause high efficiency development in the modernized education. The results suggest that platform in classroom assistant related mobile software may make the breakthrough progress in sight.
\end{abstract}

Keywords-Android; classroom assistant; software; a real-time communication platform

\section{INTRODUCTION}

The traditional teaching mode is not only inefficient but also a waste of time. Teachers usually have a lot of work tasks, if not recorded in time for some of the usual thought of teaching content, there may be some teaching information omitted. In addition, students and teachers after the class when the contact is not convenient. In other words, the teacher is also difficult to contact all the students. There are some important information which is not promptly distributed to the hands of students on the class. Students gradually raise the awareness of active learning, They need a more free time and space constraints of free learning.

Class teaching transform a simple teaching methods, for example, books or blackboard, into teaching mode combined with modern computer technology in the development of information technology. The teaching mode enhance the interest of the classroom by the expression of the rich content and the vivid picture. The mode based on mobile technology can also improve the flexibility of teaching and the teaching method combining classroom teaching and mobile equipment has attracted gradually attention with the development of mobile communication technology. Therefore, the widespread application and rapid development of mobile communication devices have also made it possible for the development of mobile-based learning. The development of mobile application software provide a real-time communication platform for students and teachers to help them to maintain the exchange of information. The platform can improve the efficiency of modern teaching.

\section{FUNCTIONAL REQUIREMENT}

Understanding the analysis of mobile phone software for users of the demand is mainly concentrated in two aspects:

First of all, the teachers often prepare some of the class materials and other materials that students prepare or preview things before the class. It is difficult for teachers to contact all students under the circumstances. The teachers always have some test question to need to answer for students. The traditional way of sending papers is a waste of time. However, the use of mobile phone software can automatically determine whether students correctly answer questions by conveniently and fast. Secondly, because of the complexity of the course, students may be confused about the course time and place. Students often do not prepare enough contents to learn and the teachers often reminds the class to prevent the students from forgetting the materials before the class, or they sometimes do not remember or forget the homework. In addition, it is boring for students to accept the traditional and simple teaching methods.

Based on the analysis of needs, the project is divided into the following modules and design: teachers and students as clients(Fig.1. and Fig.2.). Teachers and students as clients both can be provided with schedule information, examination paper information, comments information and personal information management. Teachers are responsible for issuing notice and students can accept the notification information in real-time communication. 
Teachers as clients

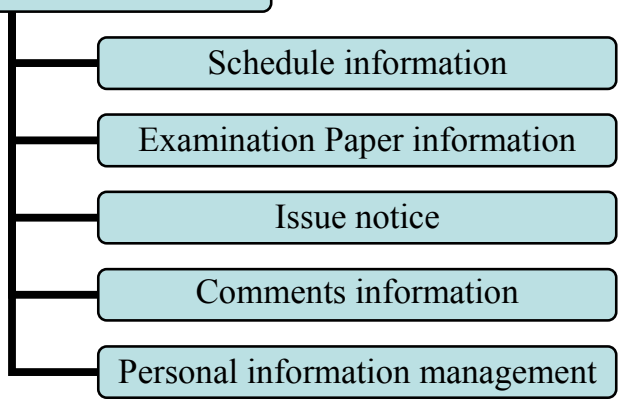

Fig. 1. Theachers As Clients.

\section{Students as clients}

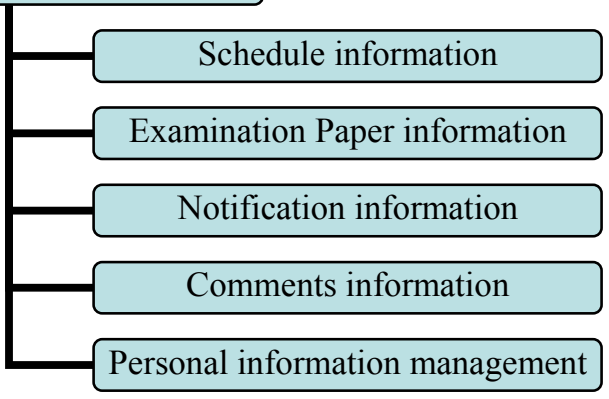

Fig. 2. Students As Clients.

\section{System Detailed Design}

\section{A. System Technology Architecture Design}

Mobile client access to obtain data through the network server.(Fig.3.)
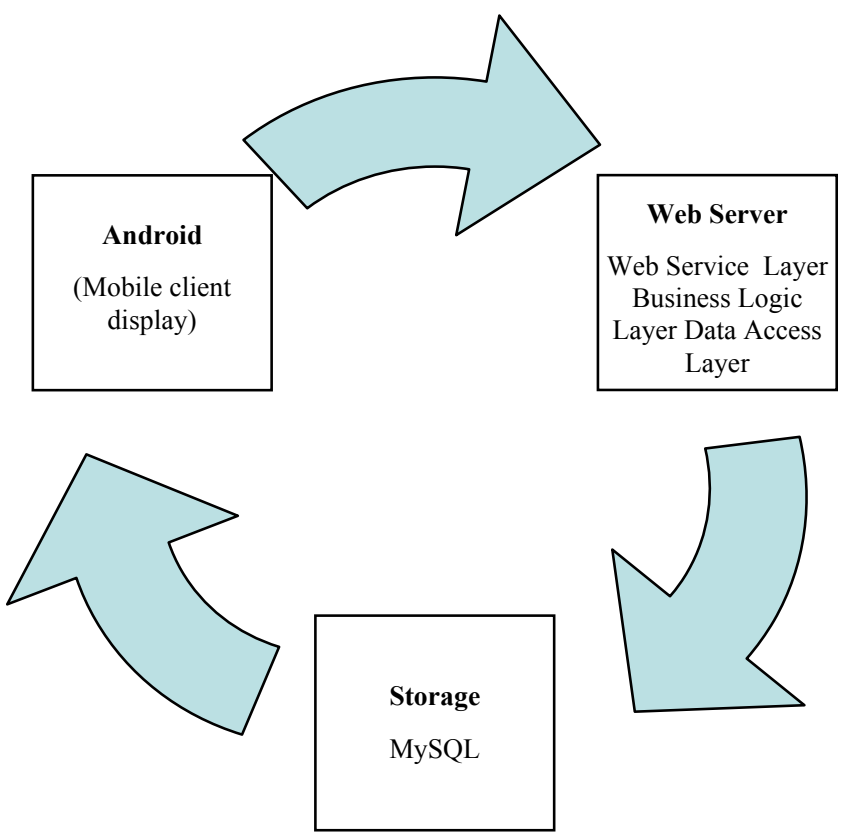

Fig. 3. System Technology Architecture
- The use of android technology ${ }^{[1]}$ respectively provide experts and ordinary users to develop two mobile client. Android not only has the characteristics of open source features, but also takes into account the client and server development basing on advance technology.

- Server-side use of web server ${ }^{[2]}$ to achieve is divided into three layers. Firstly, the bottom is the data access layer, which is responsible for database access control and management by using of iBATIS framework. Secondly, the middle layer for the business logic layer, which is the specific realization of the system functions of the core module. Finally, the upper system functions to Web Service way of external release. The project use the Restful style.

- The project uses MySQL ${ }^{[3]}$ to store data. MySQL is a small relational database management system. It is widely used in small and medium-sized internet site. Because of its small size, speed, low total cost and especially open source, many medium-sized sites select MySQL as a site database in order to reduce the total cost.

\section{B. Database Design}

It is a technology for database design to establish a database and application system. Database design is the core technology to develop software and is a variety of data storage that users needs. Specifically, the design refers to a given application environment, the construction of the optimal database model, establishment of databases and application systems to enable them to effectively store data in order to meet the needs of various users of the application. The core of the database, which base on mobile classroom-assisted APP, use to store all the information software. The system uses MySQL database. (the following table information in database storage)

- Course information table mainly stores the course number, course name, class location and other information.(TABLE I.)

TABLE I. COURSE INFORMATION TABLE

\begin{tabular}{|l|l|l|l|}
\hline \multicolumn{1}{|c|}{ Field } & \multicolumn{1}{|c|}{ Types } & \multicolumn{1}{c|}{$\begin{array}{c}\text { Field } \\
\text { Description }\end{array}$} & \multicolumn{1}{c|}{ Remarks } \\
\hline cou_id & int & id of cource & Primary Key \\
\hline cou_name & varchar(50) & cource name & \\
\hline cou_site & varchAr(50) & cource place & \\
\hline
\end{tabular}

- The notification information table mainly stores notification information including information such as the notification number, notification name, notification content and notification time. (TABLE II.)

TABLE II. NOTIFICATION INFORMATION TABLE

\begin{tabular}{|l|l|l|l|}
\hline \multicolumn{1}{|c|}{ Field } & \multicolumn{1}{|c|}{ Types } & Field Description & Remarks \\
\hline not_id & int & Notification id & Primary Key \\
\hline not_name & varchar(50) & Notification name & \\
\hline not_content & varchAr(200) & Notification contents & \\
\hline not_time & varchAr(50) & Notification time & \\
\hline
\end{tabular}


- The information table of the examination paper mainly includes information such as the number of the test paper, the name of the examination paper, the number of test questions, the writing time of the test paper and so on.(TABLE III.)

TABLE III. PAPER TEST INFORMATION TABLE

\begin{tabular}{|l|l|l|l|}
\hline \multicolumn{1}{|c|}{ Field } & \multicolumn{1}{|c|}{ Types } & \multicolumn{1}{c|}{ Field Description } & \multirow{2}{*}{ Remarks } \\
\hline pap_id & int & Paper test id & Primary Key \\
\hline pap_name & varchar(20) & Paper test name & \\
\hline pap_num & int & Paper test numbers & \\
\hline pap_time & varchAr(20) & Paper test time & \\
\hline
\end{tabular}

- The question information table mainly stores test questions information, including the number of test questions, the content of test questions, the contents of test questions, the correct choice of test questions, test scores and their papers and other information.(TABLE IV.)

TABLE IV. TEST INFORMATION TABLE

\begin{tabular}{|l|l|l|l|}
\hline \multicolumn{1}{|c|}{ Field } & \multicolumn{1}{c|}{ Types } & Field Description & Remarks \\
\hline test_id & int & Test id & Primary Key \\
\hline test_name & varchar(200) & Test contents & \\
\hline test_a_option & varchAr(50) & Test option A & \\
\hline test_b_option & varchAr(50) & Test option B & \\
\hline test_c_option & varchar(50) & Test option C & \\
\hline test_d_option & varchar(50) & Test option D & \\
\hline test_right_option & varchar(50) & Test right option & \\
\hline test_score & int & Test score & \\
\hline Pap_id & int & Belong of papar test & \\
\hline
\end{tabular}

- The evaluation information table mainly stores the evaluation information of the user and includes information such as the evaluation ID, the evaluation content, the evaluator ID and the ID of the evaluator.(TABLE V.)

TABLE V. EVALUATION INFORMATION TABLE

\begin{tabular}{|l|l|l|l|}
\hline \multicolumn{1}{|c|}{ Field } & \multicolumn{1}{|c|}{ Types } & \multicolumn{1}{c|}{ Field Description } & \multicolumn{1}{c|}{ Remarks } \\
\hline eva_id & int & Evaluation content id & Primary Key \\
\hline eva_content & varchar(20) & Evaluation content & \\
\hline eva_personid & int & Appraiser id & \\
\hline eva_topersonid & int & evaluated person id & \\
\hline
\end{tabular}

- The topic information table mainly stores the topic information to be discussed and includes information such as a topic id, a commenter's name, a topic content and a topic publication time.(TABLE VI.)

TABLE VI. TOPIC INFORMATION TABLE

\begin{tabular}{|l|l|l|l|}
\hline \multicolumn{1}{|c|}{ Field } & \multicolumn{1}{c|}{ Types } & Field Description & \multicolumn{1}{c|}{ Remarks } \\
\hline top_id & int & Topic id & Primary Key \\
\hline top_person & varchar(50) & Topic person & \\
\hline top_content & varchar(50) & Topic content & \\
\hline top_time & varchar(50) & Topic issue time & \\
\hline
\end{tabular}

\section{FUNCTION MODULE}

The platform is based on the development technology of Android and the concept of $\mathrm{PBL}^{[4]}$ approach. The project use the database of MySQL ${ }^{[5]}$ to store data and Web Serve ${ }^{[6]}$ to achieve data conversion.

The system is divided into two clients: teachers and students. On the one hand, the teachers as clients includes the timetable query, add questions, send and receive papers, check the students answering the question, the issuance of notice, classroom assessment and personal information management functions. On the other hand, the students as clients includes curriculum query, online answers, scanning the wrong topic analysis, asking the teachers, receive notifications, classroom assessment and personal information management functions.

\section{A. Login function module}

In different client login page, students and teachers log in with their own account. They can manage their own information. If you were new user, you can register in the page.

\section{B. "Schedule inquiry" function module}

In the schedule inquiry module, teachers and students can individually check their information today including class time and classrooms. They can also view the information of this semester to avoid information forgotten.

\section{C. "Paper" function module}

Teachers can view the history of the papers added, including a detailed description of each paper. They can not only view the information contained in each test paper. They can also add a new test paper including the development of the number of papers and scores and add the appropriate content for the examination papers. They choose the existing papers issued to the students, so that students to answer. The teachers can see the situation and scores of students answer and reply to the questions of the students.

Students will receive the questions in the form of the message after teachers sending the test paper. They can answer questions directly and store own situation of answer. Students can view their own history of the problem scores and their own wrong questions. Teachers can help in time for the problem students not solved.

In the examination papers module, the teacher can usually think of meaningful topics to record and even promptly issue to the students to do. Teachers will send the papers to students in the form of short messages, therefore students can do their homework at any time. At the same time you can view your answer records and wrong questions, and observe their own learning situation. Students can also ask questions to the teachers at any time. They teachers can also understand the situation students turn over the papers and get the scores. It is an effective cycle for teachers to carry out the next phase of the design of teaching work basing on the data. 


\section{Notification module}

Notification module can develop to interactive between teachers and students. Teachers can send to students in the form of notice that students need to prepare the information before the class so that teachers can easily contact all the students. There will also be emergency situations, such as temporary changes to class locations or adjustment of class time. The information can be sent to all students in the form of a notice so that each student is notified to guarantee the course to go well on.

\section{E. "Comment" function module}

The teacher can initiate a topic discussion for a specific performance of a classmate in the classroom. The students can express their views on the topic and can also express their views on the teacher's performance. They can also view others' evaluation of themselves. The interactive activities of classroom not only increase the interest of the classroom, but also mobilize the enthusiasm of the students, so that everyone can participate in classroom teaching to improve learning efficiency.

\section{F. "Personal information" function module}

Students and teachers can manage personal information in the module. The mode provide convenience to the users.

\section{SUMMARY}

Personal wireless networks, mobile data and multimedia technology base on the basis of mobile education. Teachers and students more easily achieve interactive teaching activities through the use of mobile devices to assist teaching. The classroom-assisted software of basing on Android technology development and application platform plays an important role in the teaching process. The mobile application provides students and teachers with a real-time communication platform to help teachers and students keep the information exchange conveniently. The project can meet the needs of students online learning. The platform not only facilitate the teaching of teachers, and students can also learn whether anytime or anywhere. It is significant to greatly improve the efficiency of modern teaching.

\section{ACKNOWLEDGMENT}

This research was financially supported by the National Science Foundation. The authors thank professor Zhao for her valued assistance and guidance. The authors can learn a lot of professional knowledge to improve personal ability under the guidance of the professor. In addition, the teacher educate study and life with her words and deeds.

\section{REFERENCES}

[1] Yu Bin, Android programming foundation. Southwest Jiaotong University Press, 2013.

[2] Wang Chengliang, Web development technology. Tsinghua University Press, 2013.

[3] Kong Xiangsheng, MySQL core technology and best practices. People's Posts and Telecommunications Press, 2014.

[4] Ren Yingjie, Dai Xinlai, "Study on Project-based Collaborative Learning in Network Environment," Audio-Visual Education Research, vol. 12, 2004.

[5] Li Xuefeng, MySQL the SQL statement optimization. Tsinghua University Press, 2013.

[6] Zheng Zibin, Lv Rongcong. Web service quality management. Zhejiang University Press, 2013. 